\title{
A macroscopic two-phase blood flow through a stenosed artery with permeable wall
}

\author{
Amit Medhavi* \\ Department of Mechanical Engineering, Kamla Nehru Institute of Technology, Sulanpur, India
}

\begin{abstract}
The present paper concerns with the fluid mechanical study on the effects of the permeability of the wall through an overlapping stenosis in an artery assuming that the flowing blood is represented by a macroscopic two-phase model. The expressions for the blood flow characteristics, the impedance, the wall shear stress distribution in the stenotic region, shearing stress at the stenosis throats and at the stenosis critical height have been derived. Results for the effects of permeability as well as of hematocrit on these blood flow characteristics are shown graphically and discussed briefly.
\end{abstract}

Keywords: Two-phase, hematocrit, permeable, impedance, shear stress, stenosis throat

\section{Introduction}

Arteriosclerosis or stenosis, stems from the Greek words arthero (gruel or paste) and sclerosis (hardness), is narrowing of any body passage, tube or orifice, is an abnormal and unnatural growth in the arterial wall thickness that develops at the various locations of the cardiovascular system under diseased conditions and occasionally results in to serious consequences (cerebral strokes, myocardial infarction, angina pectoris, cardiac arrests, etc.). It is believed that the disease occurs due to the deposits of the cholesterol, fatty substances, cellular waste products, calcium and fibrin in the inner lining of an artery. Irrespective of the cause, it is well known that once the constriction has developed, it brings about the significant changes in the flow field, and results into significant changes in pressure distribution, wall shear stress and the impedance (flow resistance). The flow accelerates and consequently the velocity gradient near the wall region is steeper due to the increased core velocity resulting relatively large shear stress on the wall even for a mild stenosis, in

*Corresponding author: Amit Medhavi, Department of Mechanical Engineering, Kamla Nehru Institute of Technology, Sulanpur228118, India. E-mail: amitmedhavi@yahoo.co.in. the narrowing region of the artery. With the advent of the discovery that the cardiovascular disease, stenosis is closely associated with the flow conditions and other hemodynamic factors, since the first investigation of Mann et al. [20], a large number of researchers including Young [47, 48], Young and Tsai [46], Caro et al. [7], Shukla et al. [35], Ahmed and Giddens [1], Sarkar and Jayaraman [34], Pralhad and Schultz [32], Jung et al. [13], Liu et al. [16], Srivastava [43], Misra and Shit [26], Mishra and Verma [24], Ponalagusamy [30], Layek et al. [14, 15], Joshi et al. [12], Mekheimer and Elkot [22], Tzirtzilakis [45], Mandal and coworkers [17-19], Politis et al. [28, 29], Sankar and Lee [33], Srivastava and coworkers [39, 40], Singh et al. [36], Biswas and Chakraborty [5, 6], Medhavi [21], Mishra and Siddiqui [25], Nadeem et al. [27], Mekheirmer et al. [23], Ponalagusamy and Selvi [31], Bandyopadhyay and Layek [2, 3], Chakraborty et al. [8], Srivastava et al. [44] and many others have addressed the stenotic development problems under various flow situations.

Being a suspension of corpuscles, at low shear rates blood behaves like a non-Newtonian fluid in small diameter tubes. Besides, experimental observations of Cokelet [10] and theoretical investigation of Haynes [11] indicate that blood cannot be treated 


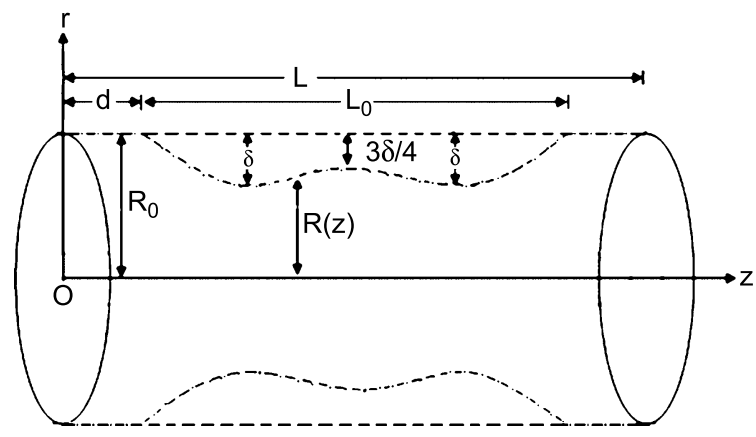

Fig. 1. Flow geometry of an overlapping stenosis in an artery with permeable wall.

as a single-phase homogeneous viscous fluid while flowing through narrow arteries (of diameter $\leq 1000$ $\mu m$ ). Srivastava and Srivastava [38] observed that the individuality of red cells (of diameter $8 \mu \mathrm{m}$ ) is significant even in such a large vessels with diameter up to hundred cells diameter and concluded that blood can be suitably represented by a macroscopic two-phase model (i.e., a suspension of red cells in plasma) in small vessels (of diameter $\leq 2400 \mu \mathrm{m}$ ). A brief discussion and survey on suspension modeling of blood flow has recently been presented by Srivastava [41]. In addition, the endothelial walls are known to be highly permeable with ultra microscopic pores through which filtration occurs. Cholesterol is believed to increase the permeability of the arterial wall. Such increase in permeability results from dilated, damaged or inflamed arterial walls. A survey of the published literature of the subject further indicates that the majority of the investigations, reported so far, have considered axisymmetric and non-symmetric single stenoses. However, in realistic situations stenosis may develop in series (multiple stenosis), overlapping or of composite in nature [40]. In view of the discussion given above, assuming that the flowing blood is represented by a macroscopic two-phase model, i.e., a suspension of erythrocytes in plasma, the research reported here is devoted to study the flow of blood through an overlapping stenosis in an artery with permeable wall. The flow in the permeable boundary is described by Darcy law which states that the rate at which a fluid flows through a permeable substance per unit area is equal to the permeability (a property of the substance through which the fluid is flowing) times the pressure drop per unit length of flow, divided by the viscosity of the fluid. To neglect the entrance, end and special wall effects the artery length is considered large enough as compared to its radius.
The wall in the vicinity of the stenosis is usually solid when stenosis develops in living vasculature.

\section{Formulation of the problem}

Consider the axisymmetric flow of blood through an overlapping stenosis, specified at the position as shown in Fig. 1, in an artery with permeable wall. The geometry of the stenosis which is assumed to be manifested in the arterial wall segment is described $[9,14,40]$ as

$$
\begin{aligned}
\frac{\mathrm{R}(\mathrm{z})}{\mathrm{R}_{0}}= & 1-\frac{3}{2} \frac{\delta}{\mathrm{R}_{0} \mathrm{~L}_{0}^{4}}\left[11(\mathrm{z}-\mathrm{d}) \mathrm{L}_{0}^{3}\right. \\
& -47(\mathrm{z}-\mathrm{d})^{2} \mathrm{~L}_{0}^{2}+72(\mathrm{z}-\mathrm{d})^{3} \mathrm{~L}_{0} \\
& \left.-36(\mathrm{z}-\mathrm{d})^{4}\right], \quad \mathrm{d} \leq \mathrm{z} \leq \mathrm{d}+\mathrm{L}_{0}, \\
= & 1 \text { otherwise, }
\end{aligned}
$$

where $R(z)$ and $R_{0}$ be respectively the radius of the tube with and without stenosis, $\mathrm{L}_{0}$ is the length of the stenosis, $\mathrm{L}$ is the length of the tube and d indicates its location, $\delta$ is the maximum projection of the stenosis into the lumen, appears approximately at the locations: $\mathrm{z}=\mathrm{d}+\mathrm{L}_{0} / 6$ and $\mathrm{d}+5 \mathrm{~L}_{0} / 6$, $\mathrm{z}$ being the axial coordinate. The height of the stenosis at $\mathrm{z}=\mathrm{d}+\mathrm{L}_{0} / 2$, called critical height, is $3 \delta / 4$.

The flowing blood is assumed to be represented by a macroscopic two-phase model, that is, a suspension of erythrocytes (red cells) in plasma. The equations describing the steady flow of a two-phase macroscopic model of blood may be expressed [37, 38] as

$$
\begin{gathered}
(1-C) \rho_{f}\left\{u_{f} \frac{\partial u_{f}}{\partial z}+v_{f} \frac{\partial u_{f}}{\partial r}\right\} \\
=-(1-C) \frac{\partial p}{\partial z}+(1-C) \mu_{s}(C) \nabla^{2} u_{f} \\
+C S\left(u_{p}-u_{f}\right) \\
(1-C) \rho_{f}\left\{u_{f} \frac{\partial v_{f}}{\partial z}+v_{f} \frac{\partial v_{f}}{\partial r}\right\} \\
=-(1-C) \frac{\partial p}{\partial r}+(1-C) \mu_{s}(C)\left(\nabla^{2}-\frac{1}{r^{2}}\right) v_{f} \\
+C S\left(v_{p}-v_{f}\right) \\
\frac{\partial}{\partial r}\left[(1-C) v_{f}\right]+(1-C) \frac{v_{f}}{r}+\frac{\partial}{\partial z}\left[(1-C) u_{f}\right]=0
\end{gathered}
$$




$$
\begin{gathered}
\rho_{\mathrm{p}}\left\{\mathrm{u}_{\mathrm{p}} \frac{\partial \mathrm{u}_{\mathrm{p}}}{\partial \mathrm{z}}+\mathrm{v}_{\mathrm{p}} \frac{\partial \mathrm{u}_{\mathrm{p}}}{\partial \mathrm{r}}\right\} \\
=-\mathrm{C} \frac{\partial \mathrm{p}}{\partial \mathrm{z}}+\mathrm{CS}\left(\mathrm{u}_{\mathrm{f}}-\mathrm{u}_{\mathrm{p}}\right), \\
\rho_{\mathrm{p}}\left\{\mathrm{u}_{\mathrm{p}} \frac{\partial \mathrm{v}_{\mathrm{p}}}{\partial \mathrm{z}}+\mathrm{v}_{\mathrm{p}} \frac{\partial \mathrm{v}_{\mathrm{p}}}{\partial \mathrm{r}}\right\} \\
=-\mathrm{C} \frac{\partial \mathrm{p}}{\partial \mathrm{r}}+\mathrm{CS}\left(\mathrm{v}_{\mathrm{f}}-\mathrm{v}_{\mathrm{p}}\right), \\
\frac{\partial}{\partial \mathrm{r}}\left[\mathrm{Cv}_{\mathrm{p}}\right]+\frac{\mathrm{C} \mathrm{v}_{\mathrm{p}}}{\mathrm{r}}+\frac{\partial[\mathrm{Cu} \mathrm{p}]}{\partial \mathrm{z}}=0,
\end{gathered}
$$

where $\nabla^{2}=\partial / \partial r^{2}+(1 / r)(\partial / \partial r)+\partial^{2} / \partial z^{2}$ is the twodimensional Laplacian operator, (r, z) are (radial, axial) coordinate (Fig. 1). $\left(\mathrm{u}_{\mathrm{f}}, \mathrm{v}_{\mathrm{f}}\right)$ and $\left(\mathrm{u}_{\mathrm{p}}, \mathrm{v}_{\mathrm{p}}\right)$ are the (axial, radial) components of the fluid particle velocities, respectively, $\mathrm{C}$ denotes the volume fraction density of the particles, $p$ is the pressure, $\mu_{\mathrm{s}}(\mathrm{C}) \simeq \mu_{\mathrm{s}}$ is the mixture viscosity (apparent or effective viscosity), $\rho_{\mathrm{f}}$ and $\rho_{\mathrm{p}}$ are respectively, the actual density of the material constituting the plasma (fluid) and the erythrocyte (particle) phases, (1-C) $\rho_{\mathrm{f}}$ and $\mathrm{C} \rho_{\mathrm{p}}$ are respectively, the fluid and the particle phases densities, $\mathrm{S}$ is the drag coefficient of interaction and the subscripts $\mathrm{f}$ and $p$ denote the quantities associated with the plasma and erythrocyte phases, respectively. The expressions for drag coefficient of interaction, $S$ and the viscosity of the suspension, $\mu_{\mathrm{s}}$ for the present study are selected [42] as

$$
\begin{gathered}
S=\frac{9}{2} \frac{\mu_{\mathrm{o}}}{\mathrm{a}_{\mathrm{o}}^{2}} \frac{4+3\left[8 \mathrm{C}-3 \mathrm{C}^{2}\right]^{1 / 2}+3 \mathrm{C}}{(2-3 \mathrm{C})^{2}}, \\
\mu_{\mathrm{s}}(\mathrm{C})=\frac{\mu_{\mathrm{o}}}{1-\mathrm{mC}},
\end{gathered}
$$

$\mathrm{m}=0.070 \exp [2.49 \mathrm{C}+(1107 / \mathrm{T}) \exp (-1.69 C)]$,

where $\mathrm{T}$ is the measure in absolute scale of temperature $(\mathrm{K}), \mu_{\mathrm{o}}$ is the constant plasma viscosity and $\mathrm{a}_{\mathrm{o}}$ is the radius of an erythrocyte.

To obtain the solution of Equations (2)-(7) is almost a formidable task. Depending however, on the size of the stenosis, certain terms in theses equations are of less significance than others. Now following the reports of Young [47], Srivastava and Rastogi [39], the equations governing the laminar, steady, one-dimensional flow of blood in an artery in the case of a mild stenosis (i.e., $\left.\delta / R_{0}<<1\right)$ are derived from Equations (2)-(7) as

$$
\begin{aligned}
(1-C) \frac{\mathrm{dp}}{\mathrm{dz}}= & (1-\mathrm{C}) \frac{\mu_{\mathrm{s}}}{\mathrm{r}} \frac{\partial}{\partial \mathrm{r}}\left(r \frac{\partial}{\partial \mathrm{r}}\right) \mathrm{u}_{\mathrm{f}} \\
& +\mathrm{CS}\left(\mathrm{u}_{\mathrm{p}}-\mathrm{u}_{\mathrm{f}}\right), \\
\mathrm{C} \frac{\mathrm{dp}}{\mathrm{dz}}= & \mathrm{CS}\left(\mathrm{u}_{\mathrm{f}}-\mathrm{u}_{\mathrm{p}}\right),
\end{aligned}
$$

The appropriate boundary conditions [4] may be stated as

$$
\begin{gathered}
\frac{\partial \mathrm{u}_{\mathrm{f}}}{\partial \mathrm{r}}=0 \text { at } \mathrm{r}=0, \\
\mathrm{u}_{\mathrm{f}}=\mathrm{u}_{\mathrm{B}} \text { and } \frac{\partial \mathrm{u}_{\mathrm{f}}}{\partial \mathrm{r}}=\frac{\alpha}{\sqrt{\mathrm{k}}}\left(\mathrm{u}_{\mathrm{B}}-\mathrm{u}_{\text {porous }}\right) \text { at } \mathrm{r}=\mathrm{R}(\mathrm{z}),
\end{gathered}
$$

where $u_{\text {porous }}=-\frac{\mathrm{k}}{\mu_{0}} \frac{\mathrm{dp}}{\mathrm{dz}}, \mathrm{u}_{\text {porous }}$ is the velocity in the permeable boundary, $u_{B}$ is the slip velocity, $\mu_{0}$ is the plasma (fluid) viscosity, $\mathrm{k}$ is Darcy number and $\alpha$ (called the slip parameter) is a dimensionless quantity depending on the material parameters which characterize the structure of the permeable material with in the boundary region.

\section{Analysis}

The expressions for velocities, $\mathrm{u}_{\mathrm{f}}$ and $\mathrm{u}_{\mathrm{p}}$ obtained as the solutions of Equations (10)-(11), subject to the boundary conditions (12)-(13), are given as

$$
\begin{aligned}
\mathrm{u}_{\mathrm{f}}= & -\frac{\mathrm{R}_{\mathrm{o}}^{2}}{4(1-\mathrm{C}) \mu_{\mathrm{s}}} \frac{\mathrm{dp}}{\mathrm{dz}}\left\{\left(\mathrm{R} / \mathrm{R}_{0}\right)^{2}-\left(\mathrm{r} / \mathrm{R}_{0}\right)^{2}\right\} \\
& +\frac{\sqrt{\mathrm{k}} \mathrm{R}_{0}}{2 \alpha(1-\mathrm{C}) \mu_{\mathrm{s}}} \frac{\mathrm{dp}}{\mathrm{dz}} \\
& \left\{\left(\mathrm{R} / \mathrm{R}_{0}\right)-\frac{2 \sqrt{\mathrm{k}} \alpha(1-\mathrm{C})}{\mathrm{R}_{0}} \mu\right\}, \\
& +\frac{4(1-\mathrm{C}) \mu_{\mathrm{s}}}{4(1-\mathrm{C}) \mu_{\mathrm{s}}} \frac{\mathrm{dp}}{\mathrm{dz}}\left\{\left(\mathrm{R} / \mathrm{R}_{0}\right)^{2}-\left(\mathrm{r} / \mathrm{R}_{0}\right)^{2}\right. \\
& \left\{\left(\mathrm{R} / \mathrm{R}_{0}\right)-\frac{\sqrt{\mathrm{k}} \mathrm{R}_{0}}{2 \alpha(1-\mathrm{C}) \mu_{\mathrm{s}}} \frac{\mathrm{dp}}{\mathrm{dz}}\right. \\
& \left(\mathrm{R}_{0}{ }^{2} \alpha(1-\mathrm{C})\right. \\
&
\end{aligned}
$$

where $\mu=\mu_{\mathrm{s}} / \mu_{0}$. 
The volumetric flow flux, $\mathrm{Q}$ is now calculated as

$$
\begin{aligned}
\mathrm{Q}= & 2 \pi(1-\mathrm{C}) \int_{0}^{\mathrm{R}} \mathrm{r} \mathrm{u}_{\mathrm{f}} \mathrm{dr}+2 \pi \mathrm{C} \int_{0}^{\mathrm{R}} \mathrm{r} \mathrm{u}_{\mathrm{p}} \mathrm{dr} \\
= & -\frac{\pi \mathrm{R}_{\mathrm{O}}^{4}}{8(1-\mathrm{C}) \mu_{\mathrm{s}}} \frac{\mathrm{dp}}{\mathrm{dz}}\left[\left(\mathrm{R} / \mathrm{R}_{0}\right)^{4}+\beta\left(\mathrm{R} / \mathrm{R}_{0}\right)^{2}\right. \\
& \left.-\frac{4\left(\mathrm{R} / \mathrm{R}_{0}\right)^{2} \sqrt{\mathrm{k}}}{\alpha \mathrm{R}_{0}^{2}}\left\{\mathrm{R}_{0}\left(\mathrm{R} / \mathrm{R}_{0}\right)-2 \sqrt{\mathrm{k}} \alpha \mu(1-\mathrm{C})\right\}\right],
\end{aligned}
$$

the third integrals in the closed form are straightforward. Using now the definitions from the published literature $[39,47]$, the expressions for the impedance (flow resistance), $\lambda$, the wall shear stress distribution in the stenotic region, $\tau_{\mathrm{w}}$, shearing stress at the stenosis throats, $\tau_{\mathrm{s}}$ and shear stresses at the stenosis critical height, $\tau_{\mathrm{c}}$ in their non-dimensional form are derived as

$$
\lambda=(1-\mathrm{C}) \mu\left\{1-\mathrm{L}_{\mathrm{o}} / \mathrm{L}+\frac{\eta}{\mathrm{L}} \int_{\mathrm{d}}^{\mathrm{d}+\mathrm{L}_{0}} \phi(\mathrm{z}) \mathrm{dz}\right\},
$$

$\overline{\text { with } \beta=8 \mathrm{C}(1-\mathrm{C}) \mu_{\mathrm{s}} / \mathrm{SR}_{0}^{2} \text {, a non-dimensional sus- }}$ pension parameter.

From Equation (16), one now obtains

$$
\frac{\mathrm{dp}}{\mathrm{dz}}=-\frac{8(1-\mathrm{C}) \mu_{\mathrm{s}} \mathrm{Q}}{\pi \mathrm{R}_{\mathrm{o}}^{4}} \phi(z)
$$

where

$$
\begin{aligned}
\phi(z)= & 1 / \mathrm{F}(\mathrm{z}), \mathrm{F}(\mathrm{z})=\left[\left(\mathrm{R} / \mathrm{R}_{0}\right)^{4}+\beta\left(\mathrm{R} / \mathrm{R}_{0}\right)^{2}\right. \\
& -\frac{4\left(\mathrm{R} / \mathrm{R}_{0}\right)^{2} \sqrt{\mathrm{k}}}{\alpha \mathrm{R}_{0}^{2}}\left\{\mathrm{R}_{0}\left(\mathrm{R} / \mathrm{R}_{0}\right)\right. \\
& -2 \sqrt{\mathrm{k}} \alpha \mu(1-\mathrm{C})\}]
\end{aligned}
$$

The pressure drop, $\Delta \mathrm{p}(=\mathrm{p}$ at $\mathrm{z}=0,-\mathrm{p}$ at $\mathrm{z}=\mathrm{L})$ across the stenosis in the tube of length, $\mathrm{L}$ is obtained as

$$
\Delta \mathrm{p}=\int_{0}^{\mathrm{L}}\left(-\frac{\mathrm{dp}}{\mathrm{dz}}\right) \mathrm{dz}=\frac{8(1-\mathrm{C}) \mu_{\mathrm{s}} \mathrm{Q}}{\pi \mathrm{R}_{\mathrm{o}}^{4}} \psi
$$

where

$$
\begin{aligned}
\psi= & \int_{0}^{\mathrm{d}}[\phi(\mathrm{z})]_{\mathrm{R} / \mathrm{R}_{0}=1} \mathrm{dz}+\int_{\mathrm{d}}^{\mathrm{d}+\mathrm{L}_{0}} \phi(\mathrm{z}) \mathrm{dz} \\
& +\int_{\mathrm{d}+\mathrm{L}_{0}}^{\mathrm{L}}[\phi(\mathrm{z})]_{\mathrm{R} / \mathrm{R}_{0}=1} \mathrm{dz} .
\end{aligned}
$$

The analytical evaluation of the second integral in the expression for $\psi$ obtained above seems to be a formidable task therefore shall be evaluated numerically whereas the analytical evaluations of first and

$$
\tau_{\mathrm{s}}=\frac{\eta(1-\mathrm{C}) \mu}{\left[\mathrm{a}^{3}+\beta \mathrm{a}-\frac{4 \mathrm{a} \sqrt{\mathrm{k}}}{\alpha \mathrm{R}_{0}^{2}}\left\{\mathrm{R}_{0} \mathrm{a}-2 \sqrt{\mathrm{k}} \alpha \mu(1-\mathrm{C})\right\}\right]}
$$

$$
\tau_{\mathrm{c}}=\frac{\eta(1-\mathrm{C}) \mu}{\left[\mathrm{b}^{3}+\beta \mathrm{b}-\frac{4 \mathrm{~b} \sqrt{\mathrm{k}}}{\alpha \mathrm{R}_{0}^{2}}\left\{\mathrm{R}_{0} \mathrm{~b}-2 \sqrt{\mathrm{k}} \alpha \mu(1-\mathrm{C})\right\}\right]}
$$

where $\quad \eta=1+\beta-\frac{4 \sqrt{\mathrm{k}}}{\alpha \mathrm{R}_{0}^{2}}\left\{\mathrm{R}_{0}-2 \sqrt{\mathrm{k}} \alpha \mu(1-\mathrm{C})\right\}$, $\mathrm{a}=1-1.25 \delta / R_{0}, \mathrm{~b}=1-0.75 \delta / R_{0}$.

$\lambda=\bar{\lambda} / \lambda_{0},\left(\tau_{\mathrm{w}}, \tau_{\mathrm{s}}, \tau_{\mathrm{c}}\right)=\left(\bar{\tau}_{\mathrm{w}}, \bar{\tau}_{\mathrm{s}}, \bar{\tau}_{\mathrm{c}}\right) / \tau_{0}, \lambda_{0}=8 \mu_{0}$ $\mathrm{L} / \pi \eta R_{0}^{4}, \tau_{0}=4 \mu_{0} \mathrm{Q} / \pi \eta R_{0}^{3}$ are the flow resistance and shear stress, respectively for a Newtonian fluid in a normal artery (no stenosis), and $\bar{\lambda}, \bar{\tau}_{\mathrm{w}}$ and $\bar{\tau}_{\mathrm{s}}$ are the impedance, wall shear stress and shearing stress at stenosis throat, respectively in their dimensional form obtained from the definitions: $\bar{\lambda}=\Delta p / Q, \bar{\tau}_{\mathrm{w}}=$ $(-\mathrm{R} / 2) \mathrm{dp} / \mathrm{dz}, \bar{\tau}_{\mathrm{s}}=\left(\bar{\tau}_{\mathrm{w}}\right)_{\mathrm{R} / \mathrm{R}_{0}=\mathrm{a}}$ and $\bar{\tau}_{\mathrm{c}}=\left(\bar{\tau}_{\mathrm{w}}\right)_{\mathrm{R} / \mathrm{R}_{0}=\mathrm{b}}$.

\section{Numerical results and discussion}

To have an estimate of quantitative effects of the various parameters on the result of the study, computer codes are develop to evaluate the analytical results obtained in Equations (13)-(16) numerically in a tube of radius $0.01 \mathrm{~cm}$ at the temperature of $37^{\circ} \mathrm{C}$. The values of the parameters selected $[43,47]$ as: $d=0 ; \mathrm{L}_{0}(\mathrm{~cm})=1 ; \mathrm{L}(\mathrm{cm})=$ 


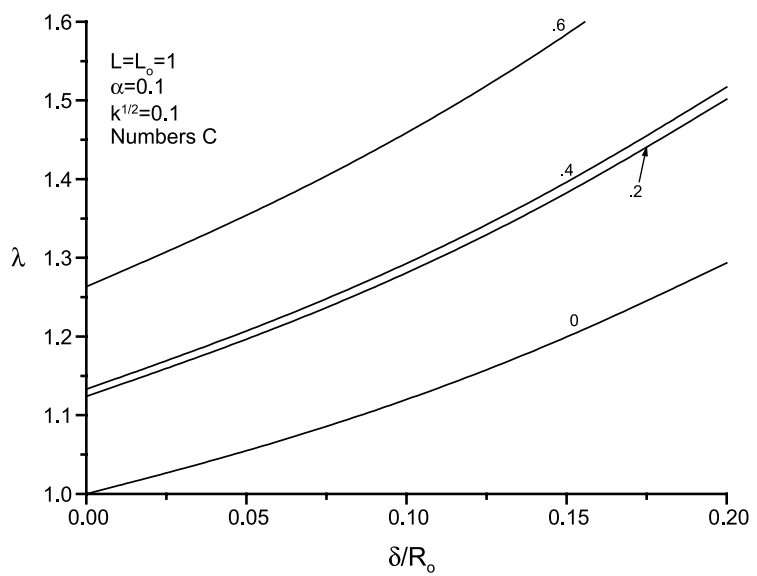

Fig. 2. Impedance, $\lambda$ versus stenosis height, $\delta / R_{0}$ for different $C$.

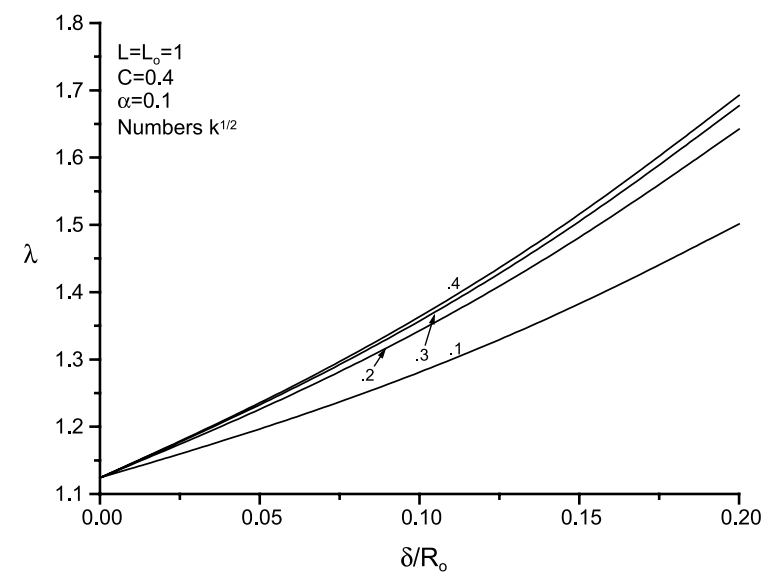

Fig. 3. Impedance, $\lambda$ versus stenosis height, $\delta / \mathrm{R}_{0}$ for different Darcy number, $\mathrm{k}^{1 / 2}$.

$1,2,5 ; \mathrm{C}=0,0.2,0.4,0.6 ; \alpha=0.1,0.2,0.3,0.4,0.5 ;$ $\sqrt{\mathrm{k}}$ (square root of Darcy number, $\mathrm{k}$ and hereafter referred as Darcy number) $=0.1,0.2,0.3,0.4 ; \delta / R_{0}=$ $0,0.05,0.10,0.15,0.20$. It is to note here that the present analysis corresponds to the flow in a normal artery (no stenosis) and to the flow of a Newtonian fluid for parameters value $\delta / R_{0}=0$ and $\mathrm{C}=0$, respectively.

The flow resistance (impedance), $\lambda$ increases with hematocrit, $\mathrm{C}$ for any given stenosis height, $\delta / R_{0}$ and also increases with the stenosis height, $\delta / R_{0}$ for any given hematocrit, $\mathrm{C}$ (Fig. 2).

The impedance, $\lambda$ increases with increasing Darcy number, $\sqrt{\mathrm{k}}$ for any given set of other parameters (Fig. 3). The flow characteristic, $\lambda$ is found to be independent of the Darcy number, $\sqrt{\mathrm{k}}$ for a normal (no

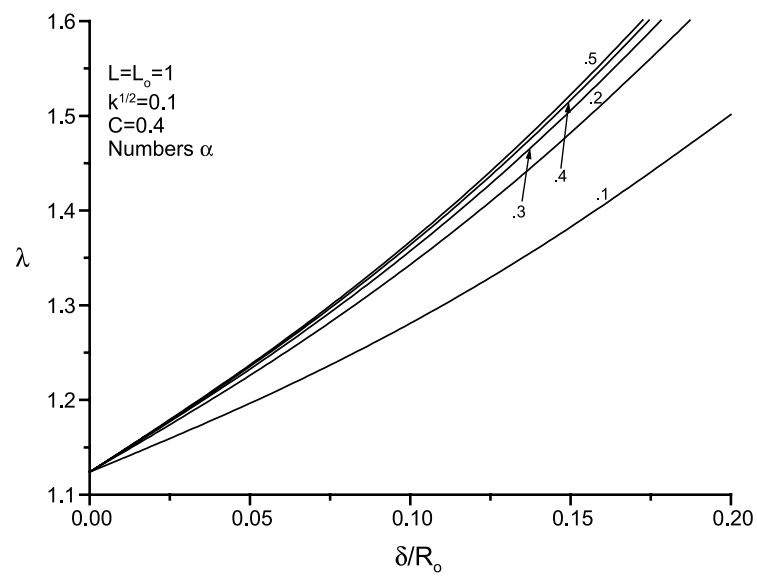

Fig. 4. Impedance, $\lambda$ versus stenosis height, $\delta / \mathrm{R}_{0}$ for different slip parameter, $\alpha$.

stenosis) artery (Fig. 3). One observes that the blood flow characteristic, $\lambda$ increases with the slip parameter, $\alpha$ for other given parameters and the magnitude of the same is independent of the slip parameter, $\alpha$ for a normal artery (Fig. 4). The impedance, $\lambda$ decreases with the increasing value of the parameter, $\mathrm{L}$ which in turn implies that $\lambda$ increases with stenosis length, $\mathrm{L}_{0}$ (Fig. 5). The resistance to flow, $\lambda$ steeply increases with the hematocrit, $\mathrm{C}$ for any given value of $\alpha, \sqrt{\mathrm{k}}$ and $\delta / R_{0}$ (Fig. 6). For other given set of parameters, the blood flow characteristic, $\lambda$ decreases from its maximal magnitude at $\sqrt{\mathrm{k}}=0$ to its asymptotic value at $\sqrt{\mathrm{k}}=0.15$ (Fig. 7). This concludes that the flow resistance assumes considerably higher magnitude in the artery without permeable wall than its corresponding value in the artery with permeable wall. One notices that flow resistance, $\lambda$ increases with the slip parameter, $\alpha$ from its minimal value at $\alpha=0.1$ and achieves an asymptotic magnitude at about $\alpha=0.5$ (Fig. 8).

The wall shear stress in the stenotic region, $\tau_{\mathrm{w}}$ increases rapidly from its approached value $\left(\right.$ at $z / \mathrm{L}_{0}=$ $0)$ and achieves its maximal magnitude at stenosis first throat located approximately at $\mathrm{z} / \mathrm{L}_{0}=1 / 6$, it then decreases steeply to its value at the stenosis critical height at $\mathrm{z} / \mathrm{L}_{0}=1 / 2$ and further increases steeply to its peak value at the stenosis second throat (same magnitude as at the stenosis first throat) located approximately at $\mathrm{z} / \mathrm{L}_{0}=5 / 6$ and finally decreases rapidly to its approached value at the end point of the constriction profile (i.e., at $\mathrm{z} / \mathrm{L}_{0}=1$ ). The blood flow characteristic, $\tau_{\mathrm{w}}$ increases with the hematocrit, $\mathrm{C}$ and the stenosis height, $\delta / R_{0}$ for any axial location in the 


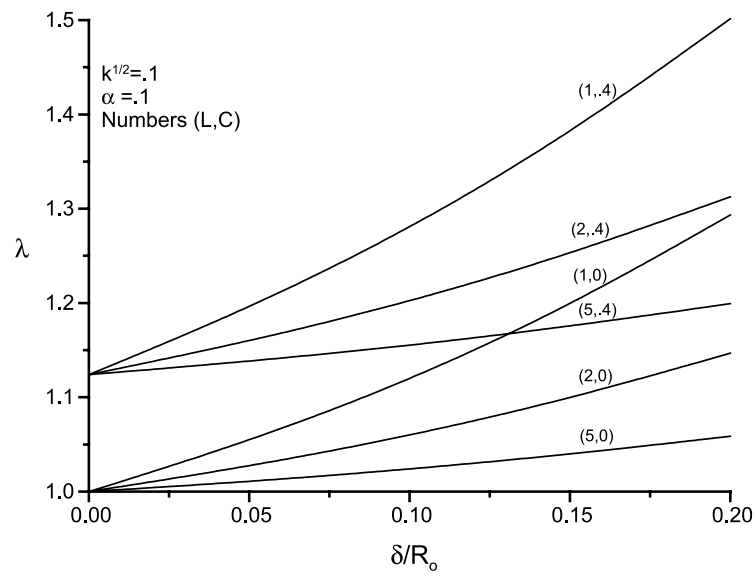

Fig. 5. Impedance, $\lambda$ versus stenosis height, $\delta / R_{0}$ for different $L$.

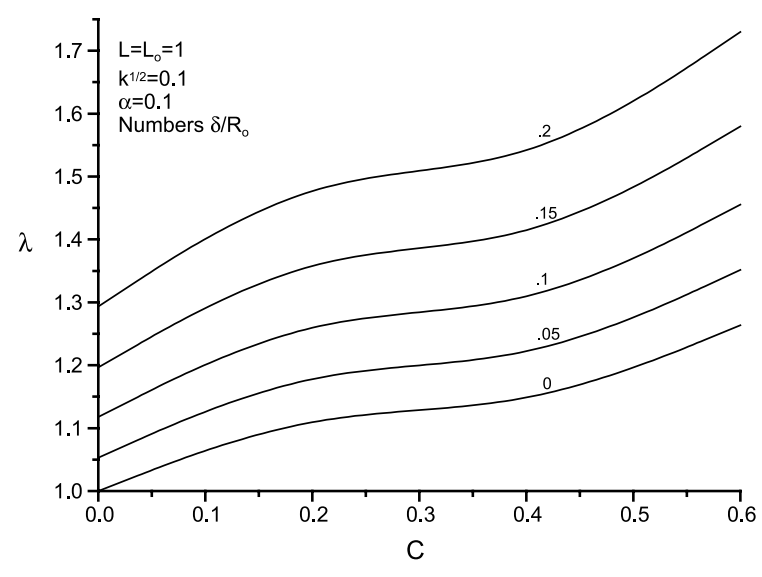

Fig. 6. Impedance, $\lambda$ versus $C$ for different stenosis height, $\delta / R_{0}$.

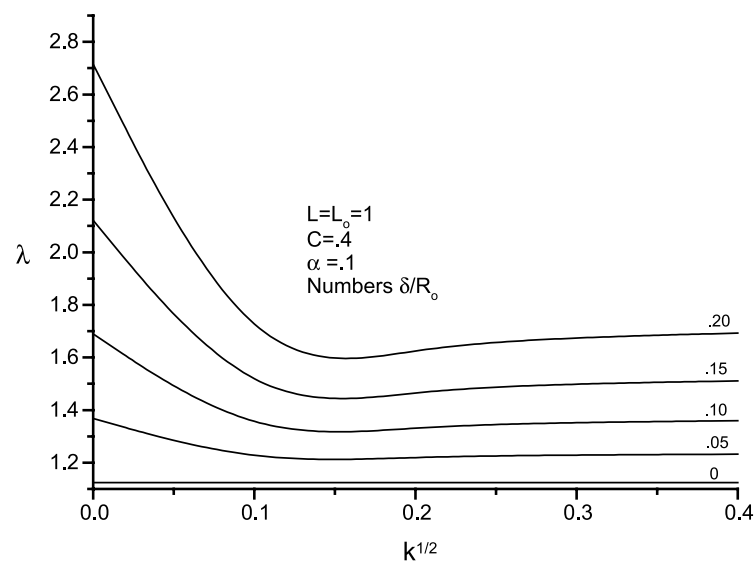

Fig. 7. Impedance, $\lambda$ versus Darcy number, $\mathrm{k}^{1 / 2}$ for different stenosis height, $\delta / \mathrm{R}_{\mathrm{o}}$.

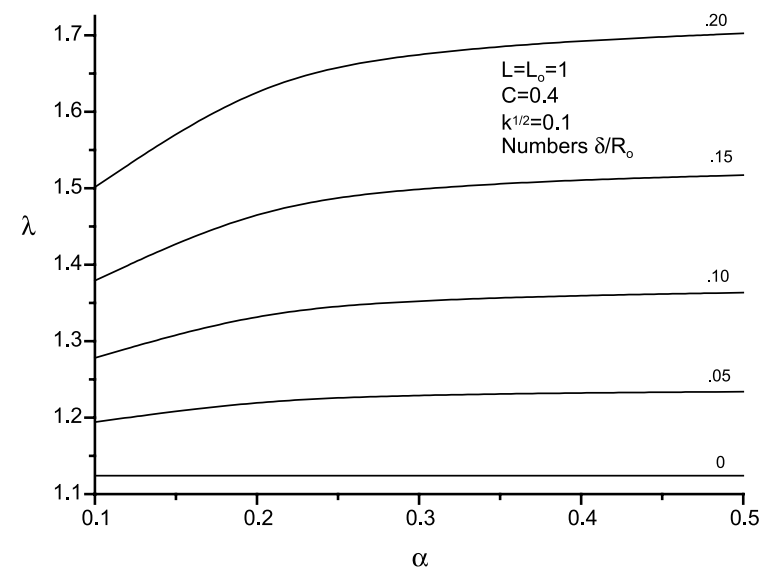

Fig. 8. Impedance, $\lambda$ versus slip parameter, $\alpha$ for different stenosis height, $\delta / \mathrm{R}_{\mathrm{O}}$.

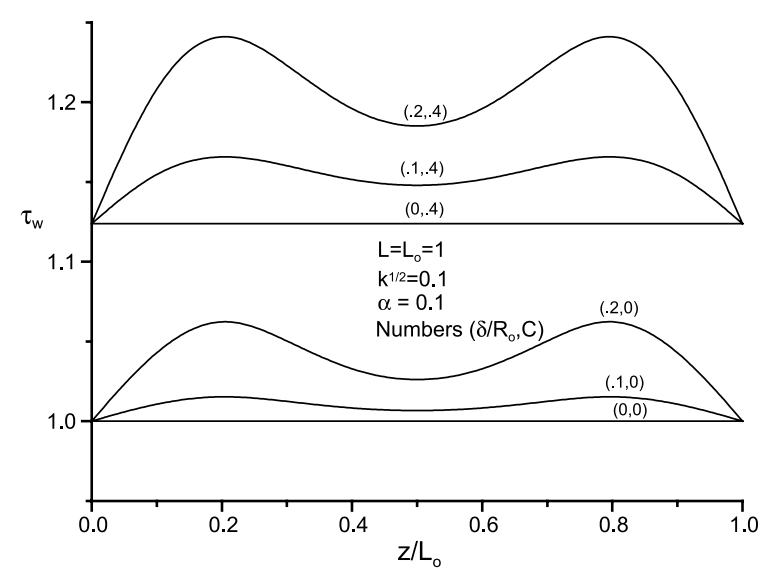

Fig. 9. Wall Shear stress distribution, $\tau_{\mathrm{W}}$ in stenotic region for different $\delta / \mathbf{R}_{\mathrm{o}}$ and $\mathrm{C}$.

stenotic region. It is to note that the blood flow characteristic, $\tau_{\mathrm{W}}$ assumes a constant magnitude for a given hematocrit, $\mathrm{C}$ for $\delta / R_{0}=0$ (Fig. 9).

For any given set of other parameters, the wall shear stress increases with the Darcy number, $\sqrt{\mathrm{k}}$ (Fig. 10). At any axial location in the stenotic region, the flow characteristic $\tau_{\mathrm{W}}$ increases with the slip parameter, $\alpha$ (Fig. 11).

The shear stress at stenosis throats, $\tau_{\mathrm{s}}$ (as observed above the shear stress at stenosis two throats assumes the same magnitude) increases with the hematocrit, $\mathrm{C}$ as well as with the stenosis height, $\delta / \mathrm{R}_{0}$ (Fig. 12). $\tau_{\mathrm{s}}$ also increases with Darcy number, $\sqrt{\mathrm{k}}$ as well as with the slip parameter, $\alpha$ (Figs. 13 and 14). The blood flow characteristic $\tau_{\mathrm{s}}$ possesses characteristic similar 


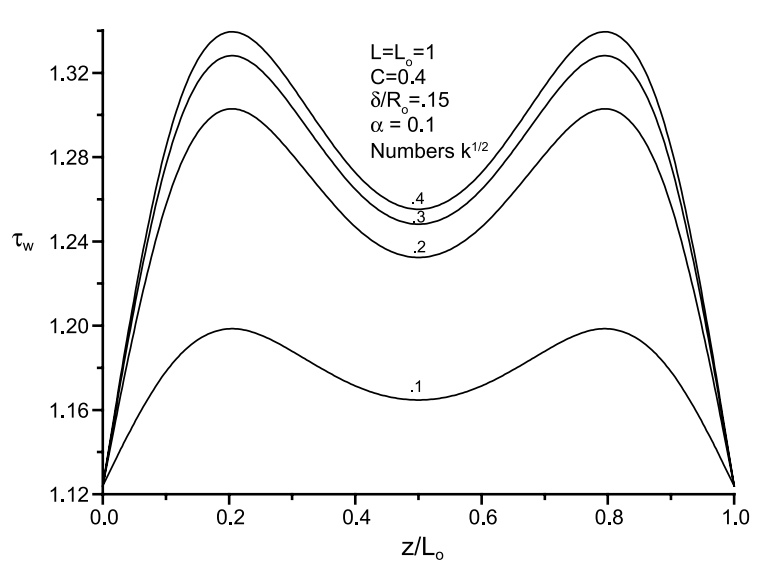

Fig. 10. Wall Shear stress distribution, $\tau_{\mathrm{w}}$ in stenotic region for different $\mathrm{k}^{1 / 2}$.

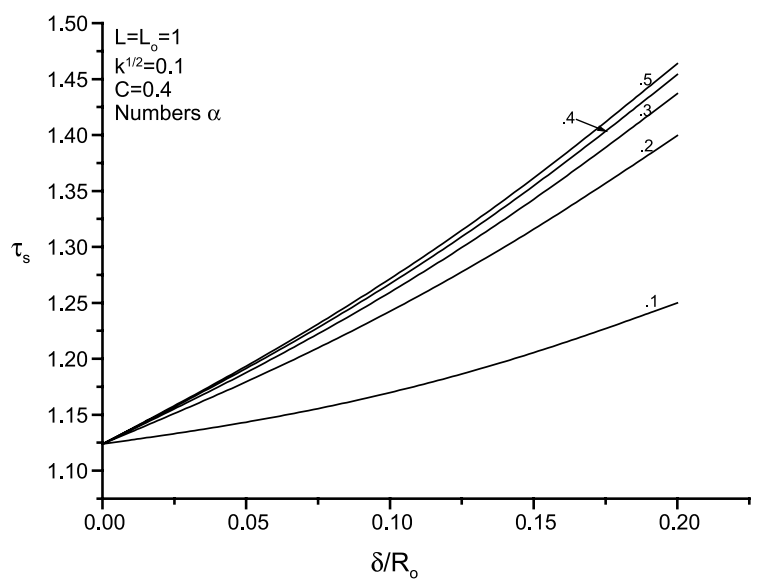

Fig. 11. Shear stress at stenosis throat, $\tau_{\mathrm{s}}$ versus stenosis height, $\delta / \mathrm{R}_{\mathrm{o}}$ for different $\alpha$.

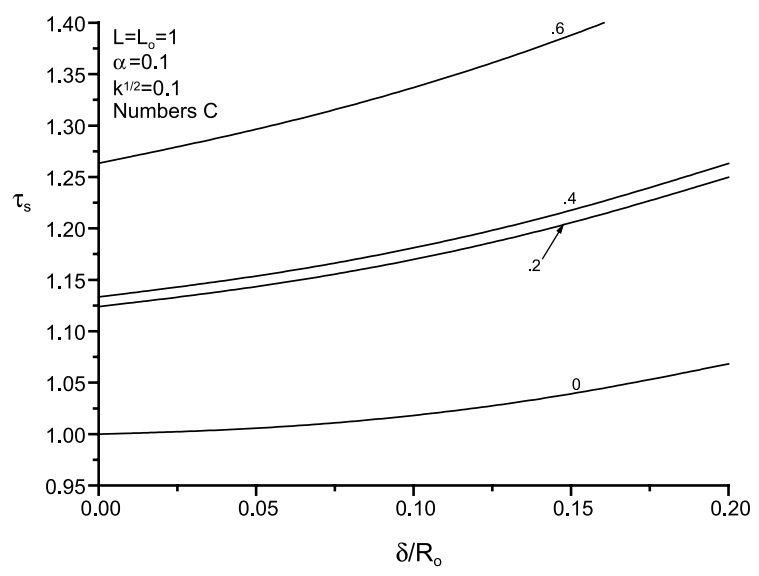

Fig. 12. Shear stress at stenosis throat, $\tau_{\mathrm{s}}$ versus stenosis height, $\delta / \mathbf{R}_{\mathrm{o}}$ for different $\mathrm{C}$.

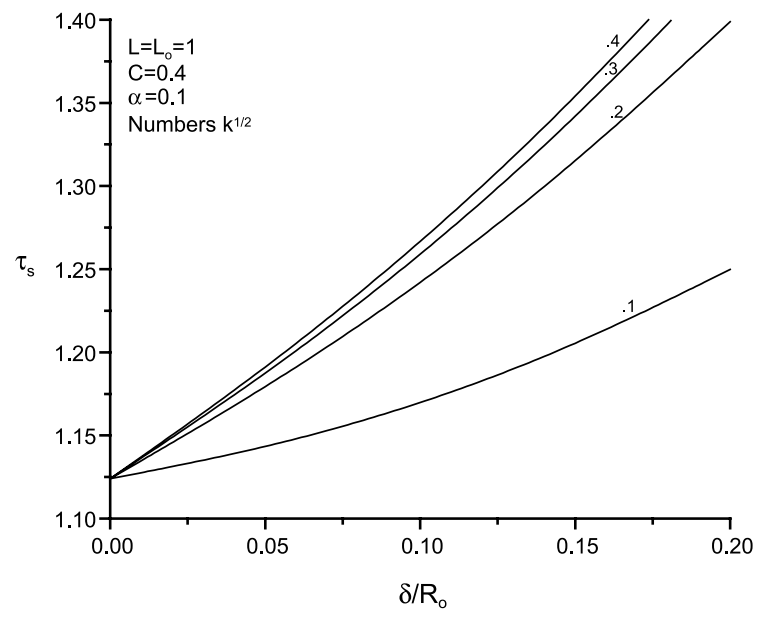

Fig. 13. Shear stress at stenosis throat, $\tau_{\mathrm{s}}$ versus stenosis height, $\delta / R_{0}$ for different $k^{1 / 2}$.

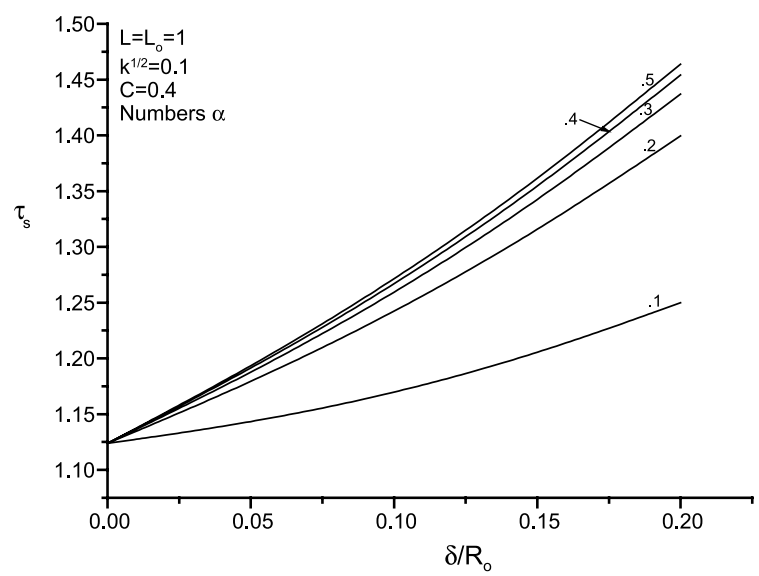

Fig. 14. Shear stress at stenosis throat, $\tau_{\mathrm{s}}$ versus stenosis height, $\delta / \mathrm{R}_{\mathrm{o}}$ for different $\alpha$.

to that of the flow resistance, $\lambda$ with respect to any parameter. The shear stress at stenosis critical height, $\tau_{\mathrm{c}}$ too increases with the hematocrit, $\mathrm{C}$, Darcy number, $\sqrt{\mathrm{k}}$, slip parameter, $\alpha$ and the stenosis height, $\delta / R_{0}$ (Fig. 15). The variations in $\tau_{\mathrm{c}}$ is similar to that of the shear stress at stenosis throats, $\tau_{\mathrm{s}}$ and the impedance, $\lambda$ with respect to any given parameter. However, $\tau_{\mathrm{c}}$ assumes significantly smaller magnitude than the corresponding magnitude of the shear stress at stenosis throats, $\tau_{\mathrm{s}}$ (Figs. 12-15). 


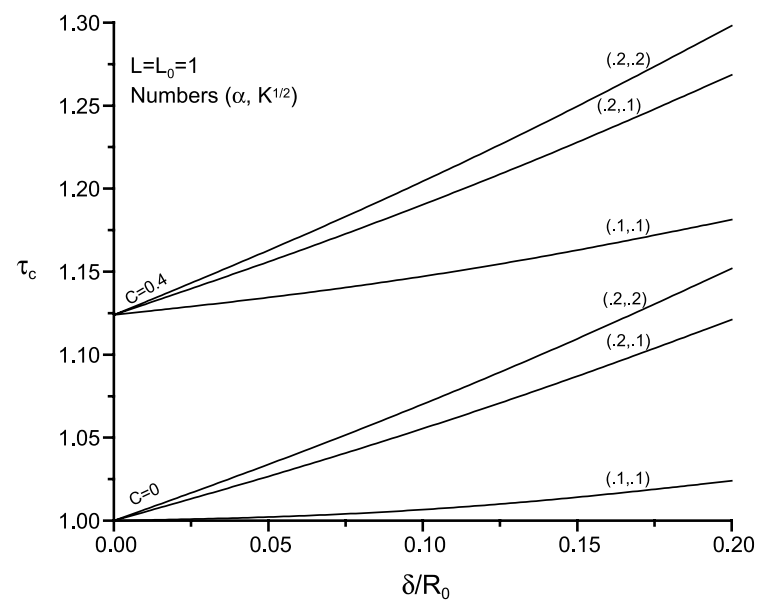

Fig. 15. Shear stress at stenosis throat critical height, $\tau_{\mathrm{c}}$ versus stenosis height, $\delta / \mathrm{R}_{\mathrm{o}}$ for different $\mathrm{C}, \alpha$ and $\mathrm{k}^{1 / 2}$.

\section{Conclusions}

A macroscopic two-phase model of blood has been applied to discuss the flow through an overlapping stenosed artery with permeable wall. The flow resistance increases with the hematocrit, stenosis size (height and length both), Darcy number as well as with the slip parameter. The informations that the impedance assumes considerably lower magnitude in the artery with permeable wall than its corresponding magnitude in the artery with non-permeable wall and the flow resistance decreases with the hematocrit seems to be of certain clinical use and the practical applications. The increasing permeability of the artery wall and the decreasing hematocrit thus seem to be helpful in the functioning of the diseased artery. The wall shear stress at any axial location in the stenotic region possesses the variations similar to that of the impedance with respect to any parameter. The magnitude of the shear stress at the two stenosis throats is same and is significantly higher than its corresponding value at the stenosis critical height. The shear stress at stenosis throats and at the stenosis critical height possess characteristic similar to that of the impedance. The magnitude of the shear stress at stenosis critical height is reasonably smaller than its corresponding value at the throats. Although, some useful conclusions have been drawn above, however, author feels that considerable amount of research is necessary to address the problem more realistically and to draw powerful conclusions.

\section{References}

[1] A.S. Ahmed and D.P. Giddens, Velocity measurements in steady flow through axisymmetric stenosis at moderate Reynolds number, J Biomech 16 (1983), 505-516.

[2] S. Bandyopadhyay and G.C. Layek, Numerical computation of pulsatile flow through a locally constricted channel, Commum Nonlinear Sci Numer Simulat 16 (2011), 252-265.

[3] S. Bandyopadhyay and G.C. Layek, Study of magnetodydrodynamic pulsatile flow in a constricted channel, Commum Nonlinear Sci Numer Simulat 17 (2012), 2434-2446.

[4] G.S. Beavers and D.D. Joseph, Boundary conditions at a naturally permeable wall, J Fluid Mech 30(1) (1967), 197-207.

[5] D. Biswas and U.S. Chakraborty, Two-layered pulsatile blood flow in stenosed artery with body acceleration and slip wall, Applc Appl Math 5(2) (2010a), 303-320.

[6] D. Biswas and U.S. Chakraborty, Pulsatile blood flow through a catherterized artery with a axially nonsymmetrical stenosis, Appl Math Sci 58(4) (2010b), 2865-2880.

[7] C.G. Caro, T.J. Pedley, R.C. Schroter and W.A. Seed, The Mechanics of the Circulation, Oxford Medical, NY, 1978.

[8] U.S. Chakraborty, D. Biswas and M. Paul, Suspension model blood flow through inclined tube with an axially nonsymmetrical stenosis, Korea-Australia Rheol J 23 (2011), 25-32.

[9] S. Chakravarty and P.K. Mandal, Mathematical modelling of blood flow through an overlapping stenosis, Math Comput Model 19 (1994), 59-73.

[10] G.R. Cokelet, The Rheology of Human Blood: In Biomechanics, Prentice-Hall, Englewood Cliffs, N.J, 1972

[11] R.H. Haynes, Physical Basis on dependence of blood viscosity on tube radius, Am J Physiol 198 (1960), 1193-1205.

[12] P. Joshi, A. Pathak and B.K. Joshi, Two layered model of blood flow through composite stenosed artery, Applications and Applied Mathematics 4(2) (2009), 343-354.

[13] H. Jung, J.W. Choi and G.C. Park, Asymmetric flows of nonNewtonian fluids in symmetric stenosed artery, Korea-Aust Rheol Journal 16 (2004), 101-108.

[14] G.C. Layek, S. Mukhopadhyay and R.S.R. Gorla, Unsteady viscous flow with variable viscosity in a vascular tube with an overlapping constriction, Int J Engg Sci 47 (2009), 649-659.

[15] G.C. Layek, S. Mukhopadhyay and S.K. Samad, Oscillatory flow in a tube with multiple constrictions, Int J Fluid Mech Res 32 (2005), 402-419.

[16] G.T. Liu, X.J. Wang, B.Q. Ai and L.G. Liu, Numerical study of pulsating flow through a tapered artery with stenosis, Chin Journal Phys 42 (2004), 401-409.

[17] P.K. Mandal, An unsteady analysis of non-Newtonian blood flow through tapered arteries with a stenosis, Int J of Nonlinear Mechanics 40 (2005), 51-164.

[18] P.K. Mandal, S. Chakravarty and A. Mandal, Numerical study on the unsteady flow of non-Newtonian fluid through diffrerently shaped arterial stenosis, Int J Comput Math $\mathbf{8 4}$ (2007a), 1059-1077.

[19] P.K. Mandal, S. Chakravarty, A. Mandal and A. Amin, Effect of body acceleration on unsteady pulsatile flow of nonNewtonian fluid through a stenosed artery, Appl Math Comput 189 (2007b), 766-779.

[20] F.C. Mann, J.F. Herrick, H.E. Essex and E.J. Blades, Effects on blood flow of decreasing the lumen of blood vessels, Surgery 4 (1938), 249-252. 
[21] A. Medhavi, On macroscopic two-phase arterial blood flow through an overlapping stenosis, E-Journal of Science and Technology 6 (2011), 19-31.

[22] K.S. Mekheimer and M.A. Elkot, Magnetic field and hall currents influences on blood flow through a stenotic arteries, Applied Mathematics and Mechanics 29 (2008), 1-12.

[23] K.S. Mekheimer, M.H. Harun and M.A. Elkot, Induced magnetic field influences on blood flow through an anisotropically tapered elastic arteries with overlapping stenosis in an annulus, Can J Phys 89 (2011), 210-212.

[24] B.K. Mishra and N. Verma, Effects of porous parameter and stenosis on the wall shear stress for the flow of blood in human body, Res J medicine and Medical Sciences 2 (2007), 98-101.

[25] S. Mishra and S.U. Siddiqui, A Mathematical model for blood flow and diffusion through stenotic capillary-tissue exchange system, E-J Sci \& Tech 6 (2011), 1-17.

[26] J.C. Misra and G.C. Shit, Blood flow through arteries in a pathological state: A theoretical study, Int J Engg Sci $\mathbf{4 4}$ (2006), 662-671.

[27] S. Nadeem, N.S. Akbar, A.A. Hendi and T. Hayat, Power law fluid model for blood flow through a tapered artery with a stenosis, Appl Math Comput 217 (2011), 7108-7116.

[28] A.K. Politis, G.P. Stavropoulos, M.N. Christolis, F.G. Panagopoulos, N.S. Vlachos and N.C. Markatos, Numerical modeling of simulated blood flow in idealized composite arterial coronary grafts: Steady state simulations, J Biomech 40(5) (2007), 1125-1136.

[29] A.K. Politis, G.P. Stavropoulos, M.N. Christolis, F.G. Panagopoulos, N.S. Vlachos and N.C. Markatos, Numerical modeling of simulated blood flow in idealized composite arterial coronary grafts: Transient flow, J Biomechanics 41(1) (2008), 25-39.

[30] R. Ponalagusamy, Blood flow through an artery with mild stenosis: A two layered model, different shapes of stenosis and slip velocity at the wall, J Appl Sci 7(7) (2007), 1071-1077.

[31] R. Ponalagusamy and R.T. Selvi, Blood flow through stenosed arteries: New formula for computing peripheral layer thickness, Int J Bio-Sci \& Bio-Tech 3 (2011), 27-37.

[32] R.N. Pralhad and D.H. Schultz, Modeling of arterial stenosis and its applications to blood diseases, Math Biosci 190 (2004), 203-220.

[33] D.S. Sankar and U. Lee, Mathematical modeling of pulsatile flow of non-Newtonian fluid in stenosed arteries, Commum Nonlinear Sci Numer Simulat 14 (2009), 2971-2981.
[34] A. Sarkar and G. Jayaraman, Corretion to flow rate-pressure drop in coronary angioplasty; steady streaming effect, J Biomech 31 (1998), 781-791.

[35] J.B. Shukla, R.S. Parihar and S.P. Gupta, Effects of peripheral layer viscosity on blood flow thorough the arterywith mild stenosis, Bull Math Biol 42 (1980), 797-805.

[36] B. Singh, P. Joshi and B.K. Joshi, Blood flow through an artery having radially non-summetric mild stenosis, Appl Math Sci 4(22) (2010), 1065-1072.

[37] L.M. Srivastava and V.P. Srivastava, Peristaltic transport of a particle-fluid suspension, Trans ASME J Biomech Engng 111 (1989), 157-165.

[38] L.M. Srivastava and V.P. Srivastava, On Two-Phase Model of Pulsatile Blood Flow with Entrance Effects, Biorheol 20 (1983), 761-777.

[39] V.P. Srivastava and R. Rastogi, Effects of hematocrit on impedance and shear stress during stenosed artery catheterization, Applications and Applied Mathematics 4 (2009), 98-113.

[40] V.P. Srivastava, R. Rastogi and R. Vishnoi, A two-layered suspension blood flow through an overlapping stenosis, Computers and Mathematics with Applications 60 (2010), $432-441$.

[41] V.P. Srivastava, A Theoretical model for blood flow in small vessels, Applc Appl Maths 2 (2007), 51-65.

[42] V.P. Srivastava and R. Srivastava, Particulate suspension blood flow through a narrow catheterized artery, Comput Math Applic 58 (2009), 227-234.

[43] V.P. Srivastava, Two-phase model of blood flow through stenosed tubes in the presence of a peripheral layer, J Biomech 29 (1996), 1377-1382.

[44] V.P. Srivastava, R. Vishnoi and P. Sinha, Response of a composite stenosis to non-Newtonian blood flow in arteries, $E-J$ Sci \& Tech 7(2) (2012), 61-70.

[45] E.E. Tzirtzilakis, Biomagnetic fluid flow in a channel with stenosis, Physica D 237 (2008), 66-81.

[46] D.F. Young and F.Y. Tsai, Flow characteristics in model of arterial stenosis - steady flow, J Biomech 6 (1973), 395-410.

[47] D.F. Young, Effects of a time-dependent stenosis of flow through a tube, Journal of Eng Ind 90 (1968), 248-254.

[48] D.F. Young, Fluid mechanics of arterial stenosis, J Biomech Eng ASME 101 (1979), 157-175. 

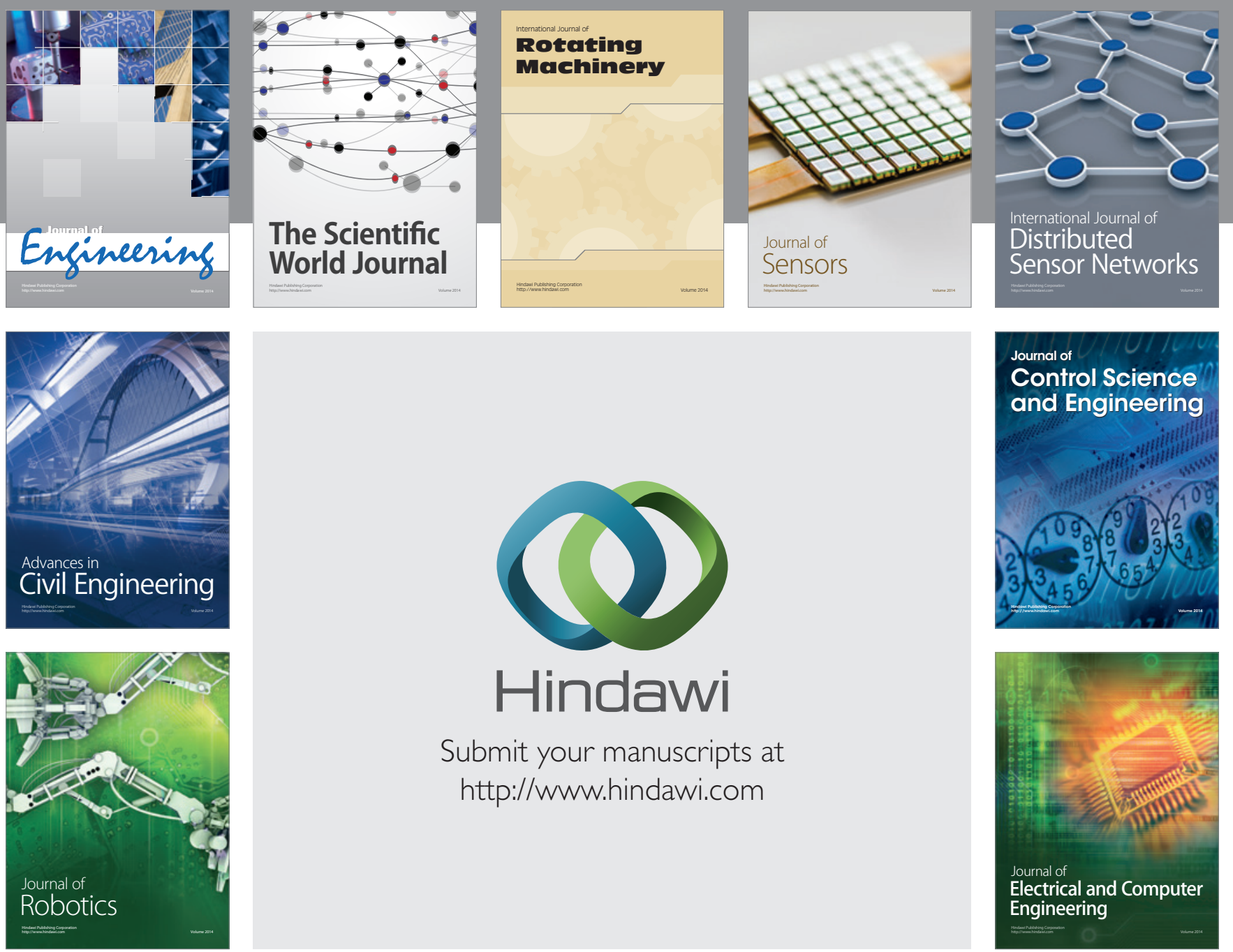

Submit your manuscripts at

http://www.hindawi.com
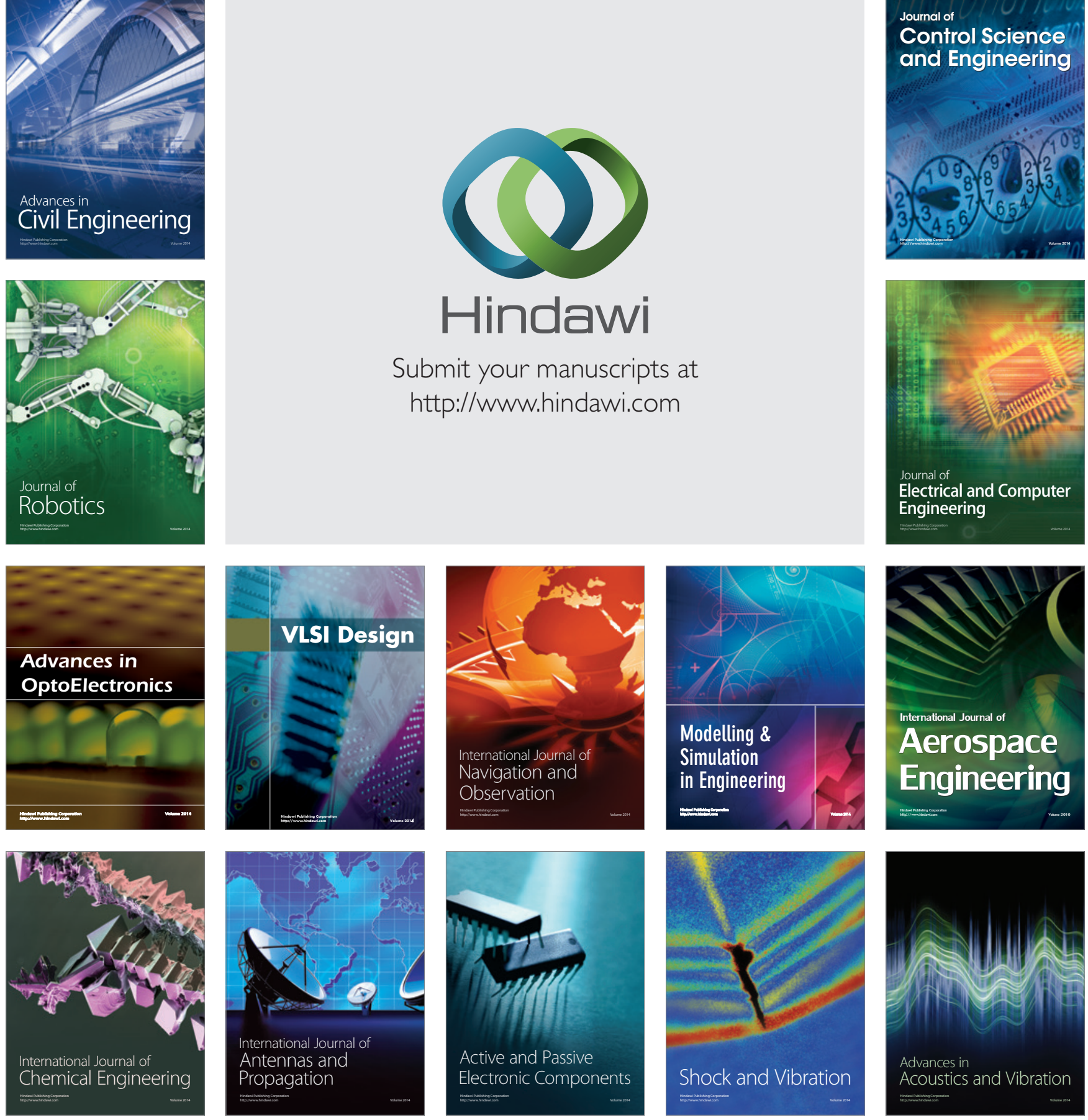